\title{
Effect of BaO on Formation Mechanisms of Silico-ferrite of Calcium and Aluminum
}

\author{
Jian-tao $\mathrm{JU}^{1,2)} \mathrm{Ke} \mathrm{MA}^{1)}$ Xiang-Dong $\mathrm{XING}^{1,2) *}$ and Gui-qing $\mathrm{ZHAO}^{3)}$ \\ 1) School of Metallurgical Engineering, Xi'an University of Architecture and Technology, Xi'an, 710055 PR China. \\ 2) Research Center of Metallurgical Engineering and Technology of Shaan Xi, Xi'an University of Architecture and Technology, \\ Xi'an, 710055 P.R. China. \\ 3) JISCO Iron and steel Research Institute, Jiayuguan, Gansu, 735100 China.
}

(Received on June 3, 2021; accepted on August 25, 2021; J-STAGE Advance published date: October $25,2021)$

\begin{abstract}
Silico-ferrites of calcium and aluminum (SFCA) are formed during the sintering process, and their changes are critical to the quality of the sinter. Aiming to further clarify the effect of $\mathrm{BaO}(0 \mathrm{mass} \%, 1$ mass $\%, 2$ mass $\%, 3$ mass $\%, 5$ mass $\%, 7$ mass $\%$, and 9 mass $\%)$ on the bonding process of SFCA. In this work, X-ray diffraction (XRD), scanning electron microscopy and energy dispersive spectroscopy (SEMEDS), thermogravimetry-differential scanning calorimeter (TG-DSC) were used to analysis the formation mechanisms of SFCA. The results indicated that the main bonding phase was SFCA. In addition, SFCA-I, $\mathrm{CF}, \mathrm{C}_{2} \mathrm{~F}$, and silicate existed in the $\mathrm{BaO}$-free sinter. Adding a small amount of $\mathrm{BaO}$ (up to 2 mass\%) could increase the decomposing temperature of SFCA and increase the formation of the needle-like SFCA. With the increase of $\mathrm{BaO}$ adding from 2 to 9 mass $\%$, the $\mathrm{BaFe}_{12} \mathrm{O}_{19}$ (FB) formed could reduce the decomposing temperature of SFCA, which deteriorated the quantity of sinter. And, $\mathrm{BaO}$ can promote the formation of $\mathrm{C}_{2} \mathrm{~F}$ in the $\mathrm{CF}$ and $\mathrm{C}_{2} \mathrm{~F}$ system, which decreased the eutectic melting temperature of $\mathrm{CF}$ and $\mathrm{C}_{2} \mathrm{~F}$.
\end{abstract}

KEY WORDS: $\mathrm{BaO}$; silico-ferrites of calcium and aluminum; bonding phase; sinter.

\section{Introduction}

The proportion of iron ore sinter in the iron raw material loaded into blast furnaces (BF) is greater than 60 mass $\%$ in the Asian region. Therefore, it is important to improve the quality of the sinter. The sinter usually contains four main parts: iron oxides $(40-70$ mass $\%)$, calcium silicates $(\leq 10$ mass $\%)$, glasses $(\leq 10$ mass $\%)$ and ferrites $(20 \%-50$ mass $\%)^{1,2)}$ According to previous studies, ${ }^{3-7)}$ the ferrite has a structure of solid solution of complex oxide with gangue contents such as $\mathrm{SiO}_{2}, \mathrm{Al}_{2} \mathrm{O}_{3}$, and $\mathrm{CaO}$. The ferrites are silico-ferrites of calcium and aluminum, also described as SFCA. ${ }^{8)}$ SFCA is one of the maximum produced minerals in iron ore sintering and has been considered as the main bonding phase during the production of industrial iron ore sinters. ${ }^{9)}$ So, it is necessary to know more about the formation mechanisms of SFCA, which have contributed to producing the high-quality sinter.

In recent years, Mumme et al. ${ }^{10)}$ explored that the SFCA had been classified as two main types according to composition, morphology, and crystal structure. The first type was a low-Fe form that was simply defined as SFCA with $\mathrm{M}_{14} \mathrm{O}_{20}$

\footnotetext{
* Corresponding author: E-mail: 3071395448@qq.com
}

stoichiometry which morphology had often been described as columnar, blocky, or lath shaped. And the second type was a high-Fe, low-Si form described as SFCA-I (it also defined as acicular) with $\mathrm{M}_{20} \mathrm{O}_{28}$ stoichiometry. ${ }^{11)}$ The SFCA and SFCA-I only involved a substitution mechanism based on the exchange of $2\left(\mathrm{Fe}^{3+}, \mathrm{Al}^{3+}\right) \leftrightarrow\left(\mathrm{Ca}^{2+}, \mathrm{Fe}^{2+}\right)+$ $\mathrm{Si}^{4+},{ }^{12)}$ but there were still some impurity elements that have the similar action in industrial sintering. It would further affect the microstructure and the content of different phases.

Nathan A. S. et al. ${ }^{13,14)}$ reported that the presence of a small amount of $\mathrm{MgO}$ during the sintering process would increase the SFCA-I content. Further to increase the addition of $\mathrm{MgO}$ could inhibit the formation of complex ferrite (SFCA) and the loss of magnesium ferrite. At the same time, it had a stabilizing effect on the structure of SFCA-I which made it difficult to melt at high temperatures. Xin-yu LI et al. discussed that the calcium ferrite, hematite, and magnetite staggered distribution in the matrix when $\mathrm{NiO}$ adding was less than 3 mass $\%$. Porosity and silicate glass phase content were both low, which contributed to improving the sinter quality. ${ }^{15)}$ The number of calcium ferrite reduced drastically with the further increased nickel adding. On the contrary, the content of $\mathrm{Ca}-\mathrm{Al}$-silicates increased which reduced the quality of the sinter. Pownceby Ian $\mathrm{C}$ et al. 
studied that the formation of Fe-rich SFCA was suppressed with the $\mathrm{TiO}_{2}$ concentration up to 6 mass $\%$. SFCA is the only Ca-rich ferrite phase to crystallize from the melt during cooling which contained more $\mathrm{Ti}$ in its crystal structure compared with SFCA-I. ${ }^{16)}$ There was a special type of iron ore containing $\mathrm{BaO}$ in China and Egypt which could have a great influence on the formation of SFCA and SFCA-I. L, X. YAN et al. reported $\mathrm{BaO}$-containing magnetite ore led to a high level of glass in the sinters even under oxidizing conditions. ${ }^{17)} \mathrm{But}$, the effect of $\mathrm{BaO}$ on the formation mechanisms of SFCA has not been studied yet.

Under the above background, the goal was to investigate the influence of the phase composition, microstructure of samples, and the melting temperature of phases. And then, the formation mechanism of SFCA with different $\mathrm{BaO}$ was clarified comprehensively in the study. These results provide technical and theoretical support for expanding the application of barium-containing iron ore in industry. This study is favorable for future research on the influence of $\mathrm{BaO}$ on the crystal structure of SFCA or SFCA-1 during cooling.

\section{Experimental}

\subsection{Preparation of Sinter Simple}

This study used analytical reagents to simulate the sintering process of iron ore fines and to avoid the influence of impurity elements on the experimental results, which were $\mathrm{Fe}_{2} \mathrm{O}_{3}(99.0 \%), \mathrm{SiO}_{2}(\geq 99.0$ mass $\%), \mathrm{CaO}(\geq 98.0$ mass $\%)$, $\mathrm{Al}_{2} \mathrm{O}_{3}$ ( $\geq 99.0$ mass $\left.\%\right), \mathrm{BaO}(\geq 98.0$ mass $\%$ ). There were nine samples, $\mathrm{BaO}$-containing were 0,1 mass $\%, 2$ mass $\%$, 3 mass $\%, 5$ mass $\%, 7$ mass $\%$, and 9 mass $\%$, respectively. The raw material compositions of sinter simples as shown in Table 1. The binary basicity $\left(\mathrm{R}=\omega_{\mathrm{CaO}} / \omega_{\mathrm{SiO} 2}\right)$ of industrial sinters was about 2.0, which depended on the requirements of the blast furnace. But, the binary basicity of all samples was 4.0, which to produce an appropriate amount of SFCA bonding phases during the sintering process for the investigation in this study. In addition, the alumina content of 5 mass\% was determined for further research. ${ }^{18,19)}$ In the complex system environment of SFCA, other components were fixed and only $\mathrm{BaO}$ content was changed.

\subsection{Method and Equipment}

All the reagents by adding anhydrous ethanol to blend for 30 mins, and then the reagents were put into a drying oven for 60 mins at $70^{\circ} \mathrm{C}$. After that, the reagents were mixed again for 30 minutes in the agate mortar to make the reagents well mixed. The mixed reagents were pressed into columnar tablets with $15 \mathrm{~mm}$ in diameter and $5 \mathrm{~mm}$ in thickness at a pressure of $5 \mathrm{MPa}$ for $3 \mathrm{~min}$ by briquetting machine. The weight of each sample was $3 \mathrm{~g}$ and the samples were placed in seven labeled alumina crucibles. Then the samples were heated to $1200^{\circ} \mathrm{C}$ at a heating rate of $10^{\circ} \mathrm{C} / \mathrm{min}$ in a muffle furnace that was presented in Fig. 1 and sintered $8 \mathrm{~h}$ in air atmosphere. The samples were quenched to room temperature in $\mathrm{N}_{2}$. Finally, one part of the samples was crushed into powder for XRD and TGA, and the other part for SEM-EDS.

\subsection{Characterization of Sinter Ores}

A part of each annealed sample was ground into a fine
Table 1. Raw material compositions of sinter samples (wt.\%)

\begin{tabular}{cccccc}
\hline Sample & $\mathrm{Fe}_{2} \mathrm{O}_{3}$ & $\mathrm{SiO}_{2}$ & $\mathrm{CaO}$ & $\mathrm{Al}_{2} \mathrm{O}_{3}$ & $\mathrm{BaO}$ \\
\hline 1 & 72.80 & 4.44 & 17.76 & 5.00 & 0.00 \\
2 & 72.07 & 4.40 & 17.58 & 4.95 & 1.00 \\
3 & 71.34 & 4.35 & 17.40 & 4.90 & 2.00 \\
4 & 70.62 & 4.31 & 17.23 & 4.85 & 3.00 \\
5 & 69.16 & 4.22 & 16.87 & 4.75 & 5.00 \\
6 & 67.70 & 4.13 & 16.52 & 4.65 & 7.00 \\
7 & 66.25 & 4.04 & 16.16 & 4.55 & 9.00 \\
\hline
\end{tabular}

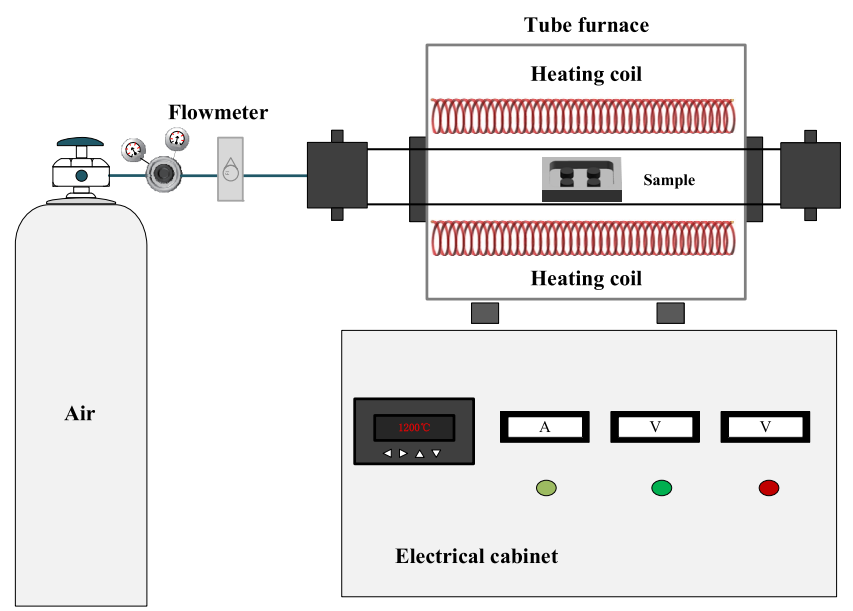

Fig. 1. Schematic diagram of the experiment equipment. (Online version in color.)

powder in an agate mortar and served with sieve $(0.28 \mathrm{~mm})$ used for XRD analysis. XRD analysis was conducted using a D8 Advance X-ray diffractometer (Bruker, Billerica, MA, USA), with $\mathrm{Cu}$ Ka used as the radiation source $(40 \mathrm{kV}, 400$ $\mathrm{mA}$ ). To obtain data by using continuous scanning mode, of which the speed of scanning was $1 \mathrm{deg} / \mathrm{min}$ and the range of 10 to $90 \mathrm{deg}$. The uncrushed samples were inserted in epoxy resin and then polished $(400,600,800,1200$, and $2000 \mathrm{CW}$ successively) for SEM-EDS (VEGA $3 \mathrm{XMU} /$ $\mathrm{XMH}$, Tescan, Czech Republic) analysis.

\subsection{TG-DSC Analysis}

The thermogravimetric (TG) and differential scanning calorimetry (DSC) methods were used to estimate the melt formation temperature of samples. A powder sample (50 $\mathrm{mg}$ ) was placed into the corundum crucible and then moved into the TG-DSC furnace. The temperature was raised nonisothermally at $10^{\circ} \mathrm{C} / \mathrm{min}$ in the air atmosphere from room temperature to $1400^{\circ} \mathrm{C}$. The melting temperature was estimated using the heat flow in terms of the DSC.

\section{Results and Discussion}

\subsection{Mineral Phase Determination}

Each group of sinter samples was triturated and taken for XRD analysis to research the phases formed after sintering with increasing $\mathrm{BaO}$ addition. Figure 2 showed the powder XRD patterns of the samples. It could be seen $\mathrm{BaO}$ could influence the diffraction peaks intensity in the sinter samples. When the content of $\mathrm{BaO}$ ranges from 0 to 2 mass\%, 


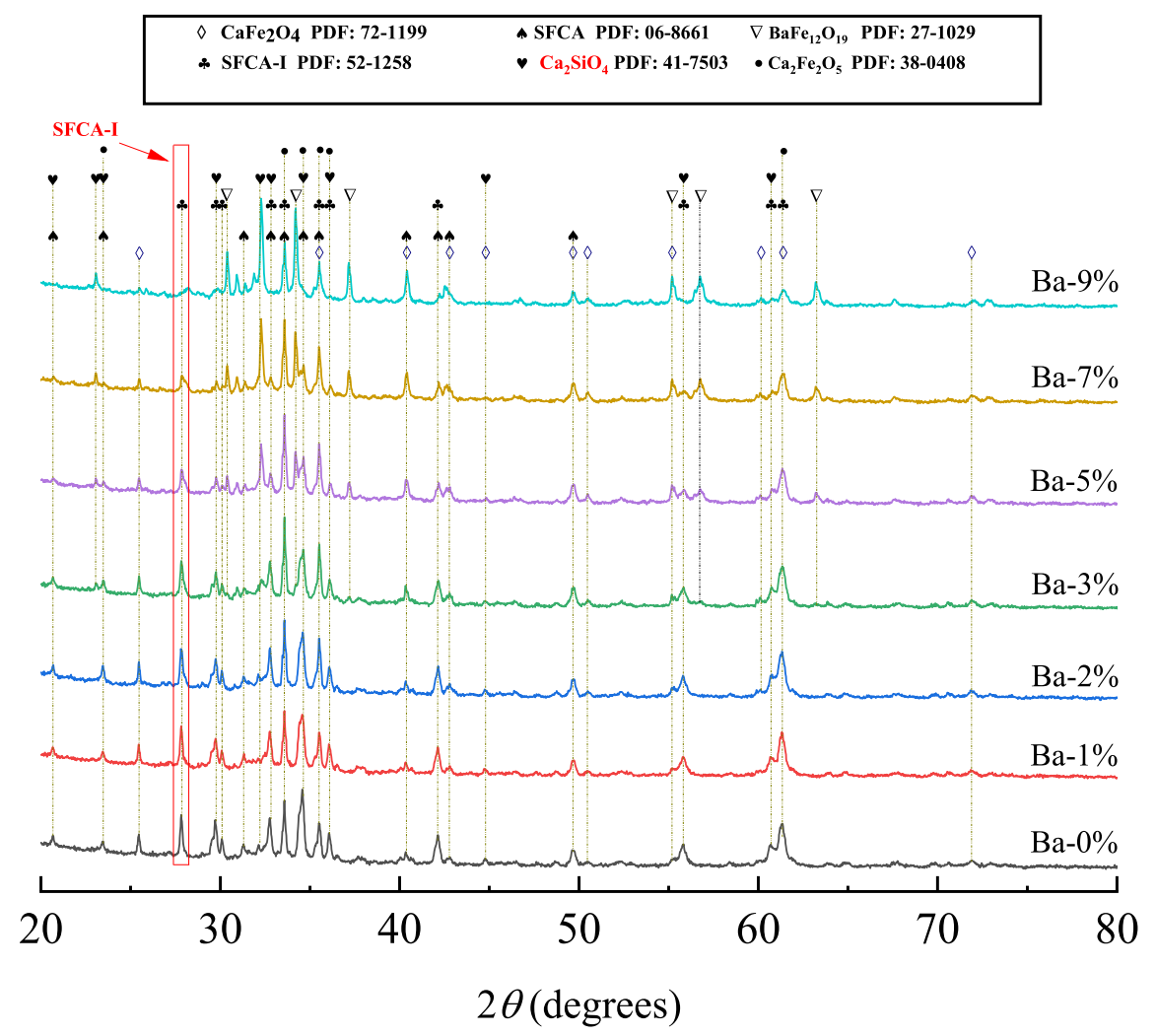

Fig. 2. XRD analysis of the powdered samples with different $\mathrm{BaO}$ mass fraction. (Online version in color.)
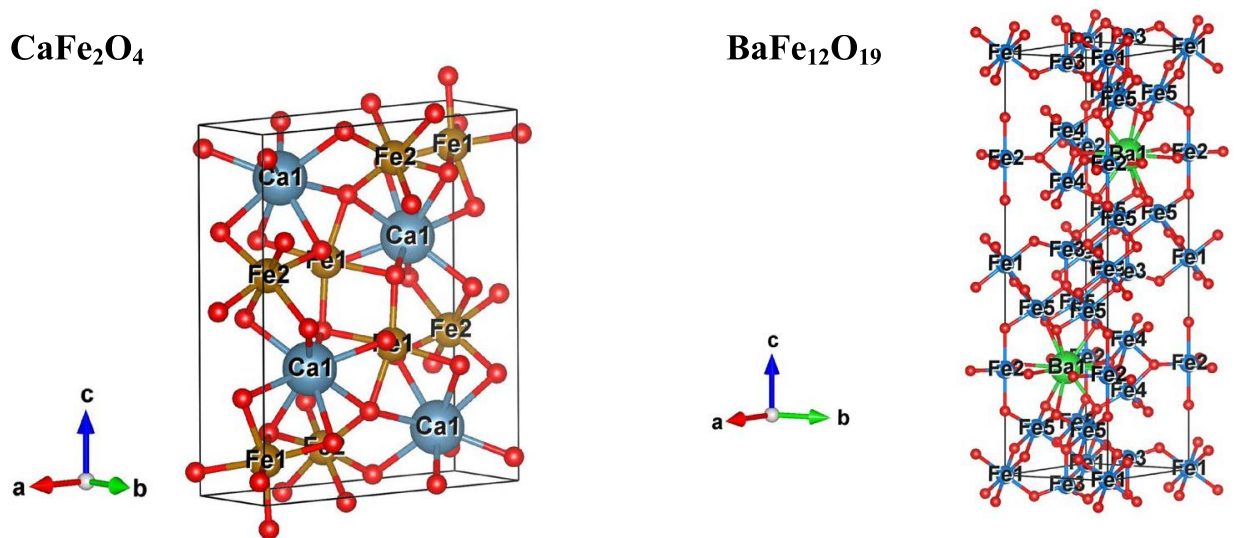

Fig. 3. Crystal structure model of $\mathrm{CaFe}_{2} \mathrm{O}_{4}$ and $\mathrm{BaFe}_{12} \mathrm{O}_{19}$. (Online version in color.)

the peaks of $\mathrm{BaO}$ could not be identified. And, the diffraction peaks intensity of SFCA, SFCA-I, $\mathrm{CaFe}_{2} \mathrm{O}_{4}(\mathrm{CF})$, and $\mathrm{Ca}_{2} \mathrm{SiO}_{4}$ had not significantly changed, indicating that $\mathrm{BaO}$ exerted a marginal influence on the phase composition with its content less than 2 mass $\%$. For the sample with 3 mass $\%$ $\mathrm{BaO}$ addition, the diffraction peaks of $\mathrm{BaFe}_{12} \mathrm{O}_{19}$ (FB) appeared and its intensity increased with $\mathrm{BaO}$ adding. However, the diffraction peaks intensity of SFCA, SFCA-I, $\mathrm{CF}$, and $\mathrm{C}_{2} \mathrm{~F}$ gradually decreased which suggested the contents of these phases decreased and the generation process was inhibited. The diffraction peaks intensity of $\mathrm{Ca}_{2} \mathrm{SiO}_{4}$ increased. When the content of $\mathrm{BaO}$ reached 9 mass $\%$, the diffraction peaks of $\mathrm{BaFe}_{12} \mathrm{O}_{19}$ was the dominant peaks, suggesting that the $\mathrm{BaFe}_{12} \mathrm{O}_{19}$ were the main phase, and SFCA and $\mathrm{CF}$ had a small change in peak positions with the $\mathrm{BaO}$ adding increased.

In addition, the $\mathrm{BaO}$ reacted with $\mathrm{Fe}_{2} \mathrm{O}_{3}$ to form $\mathrm{FB}$ needed more $\mathrm{Fe}_{2} \mathrm{O}_{3}$ compared with $\mathrm{CaO}$, as shown in reac- tions (1) and (2). The crystal structure of CF and FB were showed in Fig. 3. The more $\mathrm{Fe}^{3+}$ were contained in the crystal structure of FB.

$$
\begin{aligned}
& 6 \mathrm{Fe}_{2} \mathrm{O}_{3}+\mathrm{BaO}=\mathrm{BaFe}_{12} \mathrm{O}_{19} \\
& \Delta \mathrm{G}_{1473}^{\theta}=-817.90 \mathrm{~kJ} / \mathrm{mol} \\
& \mathrm{Fe}_{2} \mathrm{O}_{3}+\mathrm{CaO}=\mathrm{CaFe}_{2} \mathrm{O}_{4} \\
& \Delta \mathrm{G}_{1473}^{\theta}=-257.46 \mathrm{~kJ} / \mathrm{mol}
\end{aligned}
$$

This was the reason that the $\mathrm{CF}$ as the matrix reduced, which further decreased the contents of SFCA SFCA-I, $\mathrm{CaFe}_{2} \mathrm{O}_{4}(\mathrm{CF})$ phases. The Eqs. (1) and (2) showed that $\mathrm{BaO}$ was reacted easily with $\mathrm{Fe}_{2} \mathrm{O}_{3}$, which leaded to a decrease in the reaction between $\mathrm{Fe}_{2} \mathrm{O}_{3}$ and $\mathrm{CaO}$. So, the reaction between $\mathrm{CaO}$ with $\mathrm{Fe}_{2} \mathrm{O}_{3}$ was inhibited by $\mathrm{BaO}$. So, the reaction between $\mathrm{CaO}$ with $\mathrm{Fe}_{2} \mathrm{O}_{3}$ was inhibited by $\mathrm{BaO}$. It also was determined that the increase in $\mathrm{BaO}$ prompted the 
reaction between $\mathrm{CaO}$ with $\mathrm{SiO}_{2}$, which further increased the $\mathrm{Ca}_{2} \mathrm{SiO}_{4}$ formation, as shown in reaction (3).

$$
2 \mathrm{CaO}+\mathrm{SiO}_{2}=\mathrm{Ca}_{2} \mathrm{SiO}_{4}
$$

Although the reaction time in this work was much longer than that in industrial sintering, ternary calcium ferrite bearing $\mathrm{BaO}$ was still not found. It could be inferred that $\mathrm{BaO}$ may not directly react with $\mathrm{CF}$ to form a substrate liquid phase unless there were any other chemical elements. The structures of Ba-bearing SFCA phases were complicated and the contents were low, which was below the detection level and could not be discovered in the X-ray patterns. The reaction sequence involved in the formation of SFCA can be summarized in Eq. (4). ${ }^{20)}$

$$
\begin{aligned}
\mathrm{CaFe}_{2} \mathrm{O}_{4}+\mathrm{Fe}_{2} \mathrm{O}_{3}+\mathrm{CaO}+\mathrm{SiO}_{2}+\mathrm{Al}_{2} \mathrm{O}_{3}= & \mathrm{SFCA} \\
& +\mathrm{SFCA}-\mathrm{I}
\end{aligned}
$$

It was found that the SFCA and SFCA-I reduced due to the content of $\mathrm{BaO}$ exceeding 3 mass $\%$. SFCA with high strength in sinter due to its microstructure, ${ }^{21)}$ therefore the presence of SFCA as the main bonding phase in the sinter effectively improved the sinter strength, which needed to further analysis was conducted by using SEM-EDS.

\subsection{Microstructure Analysis}

To better understand the influence of adding $\mathrm{BaO}$ on microstructure, the scanning electron microscope (SEM) was used to capture the mineral phase images of the sample, and EDS was used to determine and analyze the mineral composition. The different amounts of adding $\mathrm{BaO}$ were presented in Figs. 4 and 5. Figure 4(a) showed that the SEM images of $\mathrm{BaO}$-free sinter samples. It could be seen that the columnar-like SFCA (Dark gray area) was the main morphology, and there were also CF, $\mathrm{C}_{2} \mathrm{~F}$, SFCA-I (light grey area), and silicate in the overall morphology. And, compact and dense microstructures were obtained owing to these phases had tightly distributed and intertwined with each other with no clearly observable cracks. Figures 4(b) and 4(c) shown that when $\mathrm{BaO}$ addition was increased from 1 mass $\%$ to 2 mass $\%$, the microstructure of sample compared with $\mathrm{BaO}$-free samples. The needle-like SFCA increased, and $\mathrm{CF}, \mathrm{C}_{2} \mathrm{~F}$, and SFCA-I were roughly unchanged with addition of $\mathrm{BaO}$. Few needle-like SFCAB was observed at the boundary of silicate and SFCA. Moreover, silicate gradually increased and irregular holes appeared in the matrix. The elements composition of SFCA and SFCA-I were shown in Table 2. It was observed that the content of $\mathrm{Ca}^{2+}$ and $\mathrm{Si}^{4+}$ in SFCA were reduced and $\mathrm{Al}^{3+}$ increased, which because that a small amount of $\mathrm{BaO}$ was dissolved in the SFCA. resulting the needle-like SFCA increased during the sintering process.

When the $\mathrm{BaO}$ addition from 3 mass $\%$ to 9 mass $\%$, the

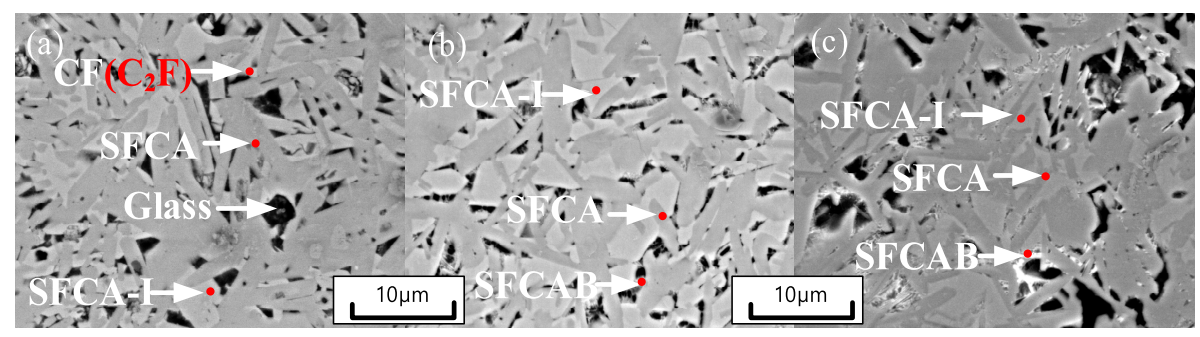

Fig. 4. The SEM images of the samples: (a) sample $1(0 \mathrm{wt} . \% \mathrm{BaO})$, (b) sample $2(1 \mathrm{wt} . \% \mathrm{BaO})$, and sample 3 (2 wt.\% $\mathrm{BaO}$ ). from the content of $\mathrm{BaO}$ range from 0 to $2 \mathrm{wt} . \%$. (Online version in color.)

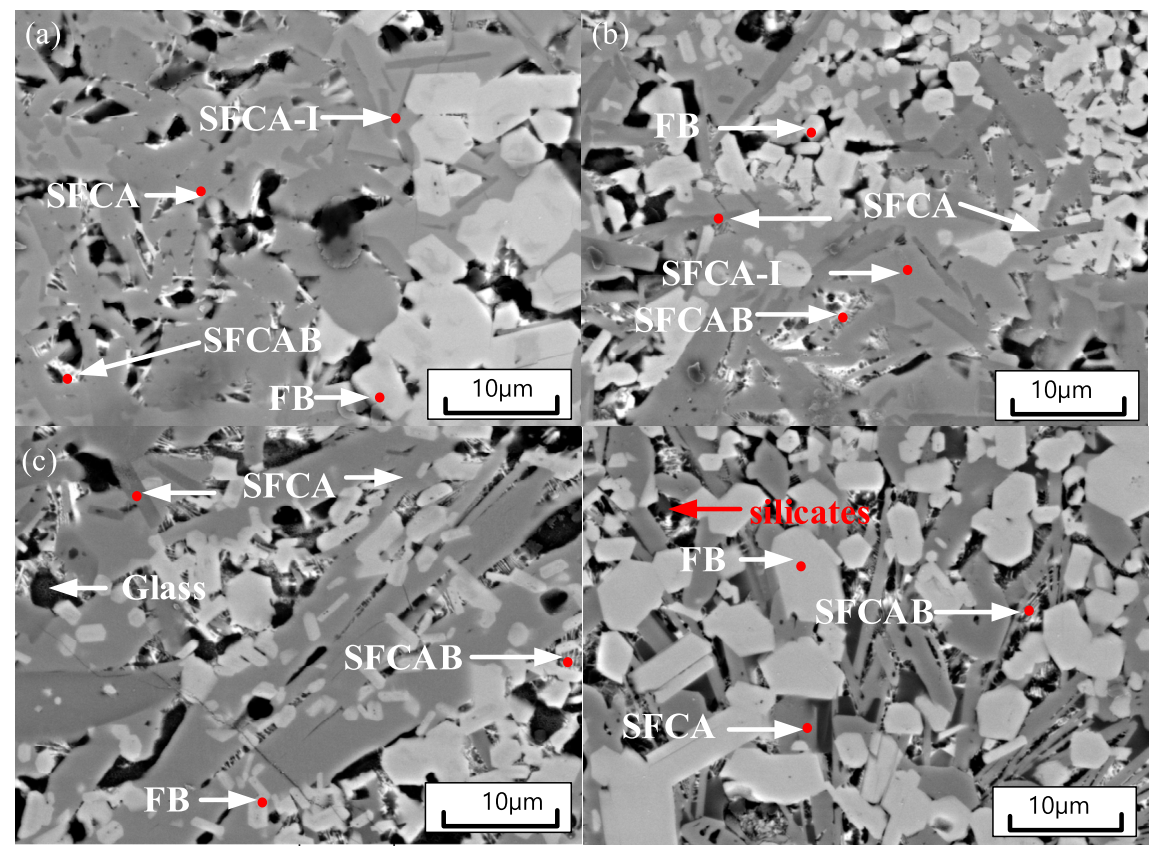

Fig. 5. The SEM images and EDS results of the samples: (a) sample 4 (3 wt.\% BaO), sample 5 ( 5 wt.\% BaO), sample 6 (7 wt. $\% \mathrm{BaO}$ ), sample 7 (9 wt.\% BaO). (Online version in color.) 
Table 2. EDS results of the samples from the content of $\mathrm{BaO}$ range from 0 to $2 \mathrm{wt} . \%$.

\begin{tabular}{ccccccc}
\hline Elements & $\mathrm{Fe}$ & $\mathrm{Ca}$ & $\mathrm{Al}$ & $\mathrm{Si}$ & $\mathrm{Ba}$ & $\mathrm{O}$ \\
\hline SFCA & 51.64 & 11.75 & 2.63 & 2.43 & - & 31.55 \\
SFCA-I & 51.79 & 16.21 & 1.00 & - & - & 31.00 \\
SFCA & 51.10 & 11.94 & 2.45 & 1.52 & - & 32.98 \\
SFCA-I & 52.50 & 15.89 & 0.59 & - & - & 31.02 \\
SFCAB & 49.96 & 9.04 & 3.30 & 5.25 & 4.41 & 28.03 \\
SFCA & 48.68 & 11.36 & 2.55 & 3.33 & - & 34.08 \\
SFCA-I & 53.76 & 17.03 & 0.52 & - & - & 28.69 \\
SFCAB & 38.29 & 6.14 & 5.38 & 4.38 & 15.87 & 29.94 \\
\hline
\end{tabular}

microstructures of samples were depicted in Fig. 5. As depicted in Fig. 5(a), SFCA was still the main mineral phase component of the substrate, and a small amount of irregular silicate and pores were found. However, a large amount of needle-like SFCA disappeared, and grained and plate-like SFCA appeared. FB precipitated on the edge of the substrate, and it was off-white in the shape of a block. Figure 5(b) shown that SFCA in the form of grained and plate-like was still the main mineral phase component of the substrate, and irregular silicates increased and pores become larger. A large amount of FB (off-white small-grained) precipitated from the SFCA and SFCA-I phases, which enlarged the diameter of the pores and reduced the strength of the entire bonding phase. As shown in Fig. 5(c), the needle-like SFCA in the matrix disappeared completely and existed in a platelike form. With the increase of $\mathrm{BaO}$ content, the newlyemerged FB particles gradually increased and transformed into a columnar evenly distributed on the substrate. However, the increased of FB affected the strength of the sintered sample. Figure 5(d) showed that a lot of bulk-grained FB was existed in the sinter, and the plate-like SFCA was distributed in the crevices. Tables 3 and $\mathbf{4}$ showed that the EDS analysis results of the four sinter samples, exhibiting the chemical composition of the SFCA, SFCA-I, FB, and $\mathrm{SFCAB}$. The $\mathrm{Si}^{4+}$ was no found in $\mathrm{FB}$, and a large amount of $\mathrm{Si}^{4+}$ was present in the SFCA mineral phase.

The SEM and EDS analysis results showed that when the $\mathrm{BaO}$ adding exceeded 2 mass $\%$, the new phase $\mathrm{FB}$ was precipitated from the SFCA phase. It was observed that there was not $\mathrm{Si}^{4+}$ existed in the $\mathrm{FB}$ and most of $\mathrm{Si}^{4+}$ was present in the SFCA, suggesting that the presence of barium prevented the diffuse of $\mathrm{Si}^{4+}$ from SFCA to $\mathrm{FB}$ since the $\mathrm{Si}^{4+}$ was not detected in the SFCA, which was similar to the results of $\mathrm{Li}$ et $a l^{22)}$ It was also found that the $\mathrm{Ba}^{2+}$ was concentrated in the $\mathrm{FB}$ phase, but there was still a small amount of $\mathrm{Ca}^{2+}$ and $\mathrm{Al}^{3+}$ as the content of barium oxide increases. Because the content of $\mathrm{Ca}^{2+}$ and $\mathrm{Al}^{3+}$ in the melt was much higher than $\mathrm{Ba}^{2+}$, a little of $\mathrm{Ca}^{2+}$ and $\mathrm{Al}^{3+}$ probably diffused into $\left(\mathrm{Ba}_{1-\mathrm{x}} \mathrm{Fe}_{\mathrm{x}}\right) \cdot \mathrm{Fe}_{2} \mathrm{O}_{3}$.

\subsection{Thermal Analysis}

The data of $700-1400^{\circ} \mathrm{C}$ was used to draw thermogravimetric and differential scanning calorimetry curves (TG-DSC curves) to facilitate the analysis of the experimental results. As depicted in Fig. 6, the TG-DSC curves of the samples with $\mathrm{BaO}$ contents $(0,1$ mass $\%, 2$ mass $\%$,
Table 3. Barium -containing region composition of four sinter samples.

\begin{tabular}{ccccccc}
\hline Elements & $\mathrm{Fe}$ & $\mathrm{Ca}$ & $\mathrm{Al}$ & $\mathrm{Si}$ & $\mathrm{Ba}$ & $\mathrm{O}$ \\
\hline FB (a) & 57.79 & 1.12 & 1.6 & - & 11.08 & 28.41 \\
FB (b) & 58.58 & 4.99 & 1.6 & - & 7.28 & 27.55 \\
FB (c) & 56.92 & 1.04 & 1.77 & - & 11.51 & 28.75 \\
FB (d) & 57.57 & 0.62 & 2.08 & - & 12.18 & 27.54 \\
\hline
\end{tabular}

Table 4. EDS results of the samples from the content of $\mathrm{BaO}$ range from $3 \mathrm{wt} . \%$ to $9 \mathrm{wt} . \%$.

\begin{tabular}{ccrcccc}
\hline Elements & $\mathrm{Fe}$ & \multicolumn{1}{c}{$\mathrm{Ca}$} & $\mathrm{Al}$ & $\mathrm{Si}$ & $\mathrm{Ba}$ & $\mathrm{O}$ \\
\hline SFCA & 51.53 & 9.62 & 4.21 & 1.99 & - & 32.66 \\
SFCA-I & 51.89 & 15.39 & 1.11 & - & - & 31.61 \\
SFCAB & 48.17 & 5.21 & 3.83 & 1.7 & 8.76 & 32.33 \\
SFCA & 52.63 & 14.42 & 2.52 & 0.88 & - & 29.55 \\
SFCA-I & 52.43 & 16.86 & 0.66 & - & - & 30.05 \\
SFCAB & 30.26 & 5.48 & 6.62 & 2.22 & 29.13 & 26.29 \\
FB & 55.65 & 2.27 & 2.06 & - & 11.21 & 28.81 \\
SFCA & 49.15 & 14.44 & 2.21 & 0.84 & - & 33.36 \\
SFCAB & 34.37 & 8.76 & 4.49 & 2.25 & 16.9 & 33.21 \\
FB & 58.01 & 1.43 & 1.91 & - & 9.75 & 28.89 \\
SFCA & 43.95 & 17.33 & 3.22 & 1.94 & - & 33.56 \\
SFCAB & 48.83 & 7.92 & 2.85 & 1.18 & 8.7 & 30.52 \\
FB & 57.88 & 0.99 & 2.08 & - & 11.82 & 27.23 \\
\hline
\end{tabular}

3 mass $\%, 5$ mass $\%, 7$ mass $\%$, and 9 mass $\%$ ) were showed. As the temperature of sample increased from $700^{\circ} \mathrm{C}$ to $1400^{\circ} \mathrm{C}$, there were mainly two endothermic peaks in these seven samples, which were referred to as A and B respectively during the heating process. According to the binary phase diagram of $\mathrm{CaO}-\mathrm{Fe}_{2} \mathrm{O}_{3}$, the endothermic peak A $\left(\mathrm{T}=1208^{\circ} \mathrm{C}\right)$ was corresponding to the eutectic melting temperature of $\mathrm{CF}$ and $\mathrm{C}_{2} \mathrm{~F} .{ }^{23,24)}$ The endothermic peak $\mathrm{B}$ $\left(\mathrm{T}=1280^{\circ} \mathrm{C}\right)$ was close to the decomposing temperature of SFCA, which was similar to the result of Zhe Wang et $a l^{25)}$ For these seven experiments, two obvious weightless stages, which respectively were $1200-1300^{\circ} \mathrm{C}$, and $1300-1400^{\circ} \mathrm{C}$.

Between $1200-1300^{\circ} \mathrm{C}$, the weight of the samples (TG value) went down from about $1200^{\circ} \mathrm{C}$, which corresponded to the endothermic peak appearing on the DSC curve. The key reason for mass loss was the decomposition of numerous $\mathrm{Fe}_{2} \mathrm{O}_{3}$ in the system. The equation of the decomposition was:

$$
\mathrm{Fe}_{2} \mathrm{O}_{3} \rightarrow \mathrm{FeO}+\mathrm{O}_{2}
$$

The formula (5) is the decomposition reaction of $\mathrm{Fe}_{2} \mathrm{O}_{3}$. After $1300^{\circ} \mathrm{C}$, the TG curve dropped slowly. It indicated that fewer $\mathrm{Fe}_{2} \mathrm{O}_{3}$ decomposed in the SFCA phase.

The development of the sinter bonding phases may include the appearance of a low-melting phase, and the second liquid phase generated. The sinter strength was improved by the bonding phase agglomeration during cooling. ${ }^{26)}$ The peak area of the DSC curves corresponded to 

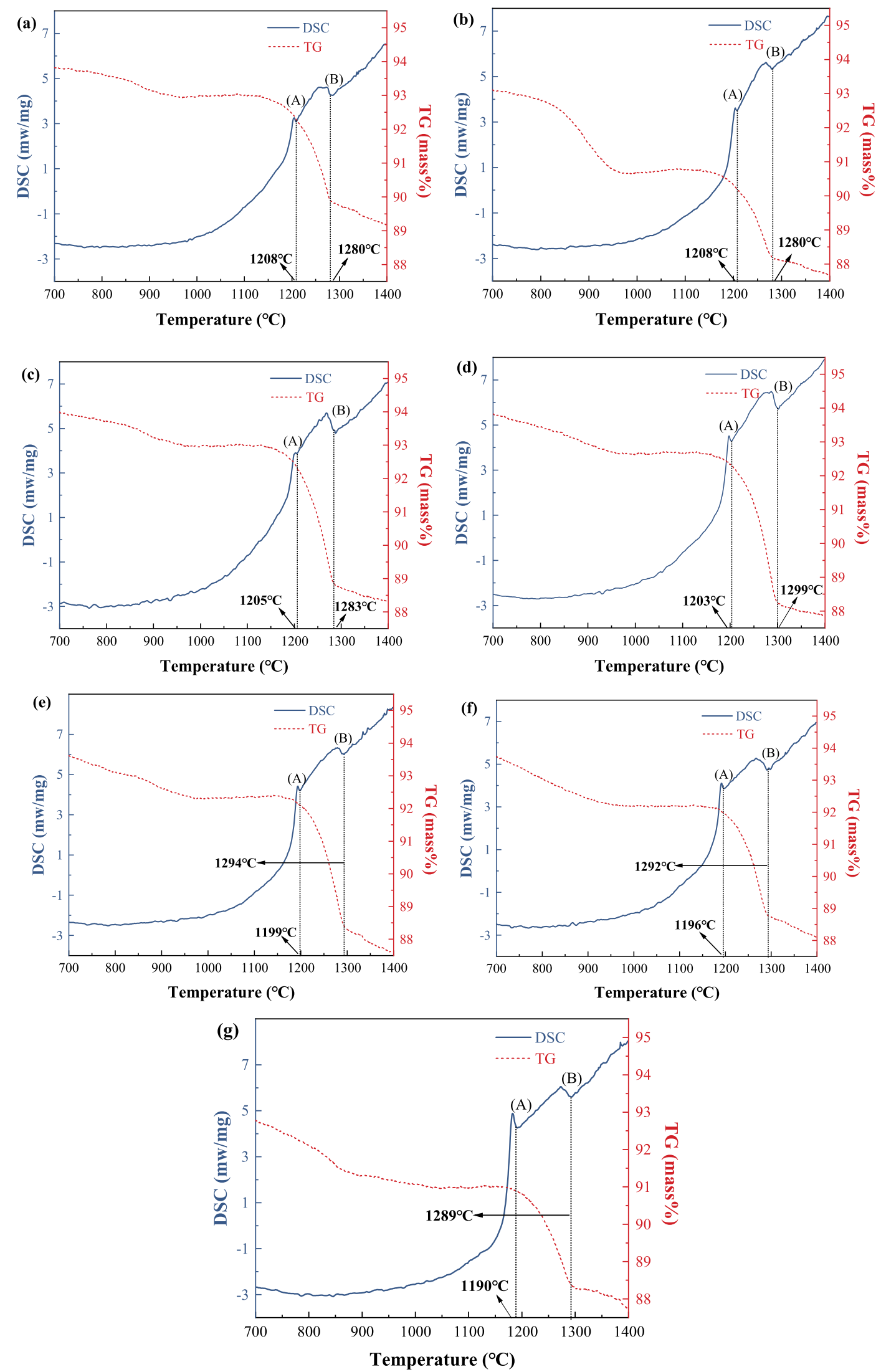

Fig. 6. Curves of the mixed powders with different $\mathrm{BaO}$ contents. (a) 0 , (b) 1 wt.\%, (c) 2 wt.\%, (d) 3 wt.\%, (e) 5 wt.\%, (f) 7 wt.\%, (g) 9 wt.\%. (Online version in color.)

the amount of liquid phase produced and the amount of liquid phase depended on the CF and SFCA phases content. When the content of $\mathrm{BaO}$ range from 0 to 2 mass $\%$, the area of the endothermic peak A changed less as shown in Fig. 7(a), which suggested that the formation of CF liquid phase was relatively small. The area of the endothermic peak B increased was showed in Fig. 7(b) and the decomposing temperature of SFCA went up as shown in Fig. 8(b), it could determine that the formation of the SFCA liquid phase had gone up significantly. This indicated that a small amount of 


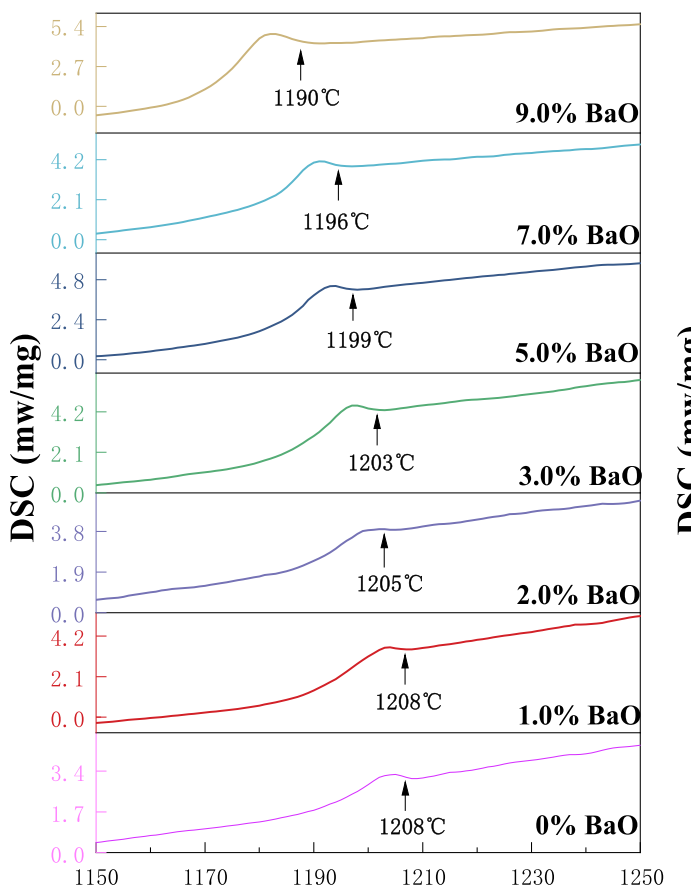

(a)

Temperature $\left({ }^{\circ} \mathrm{C}\right)$

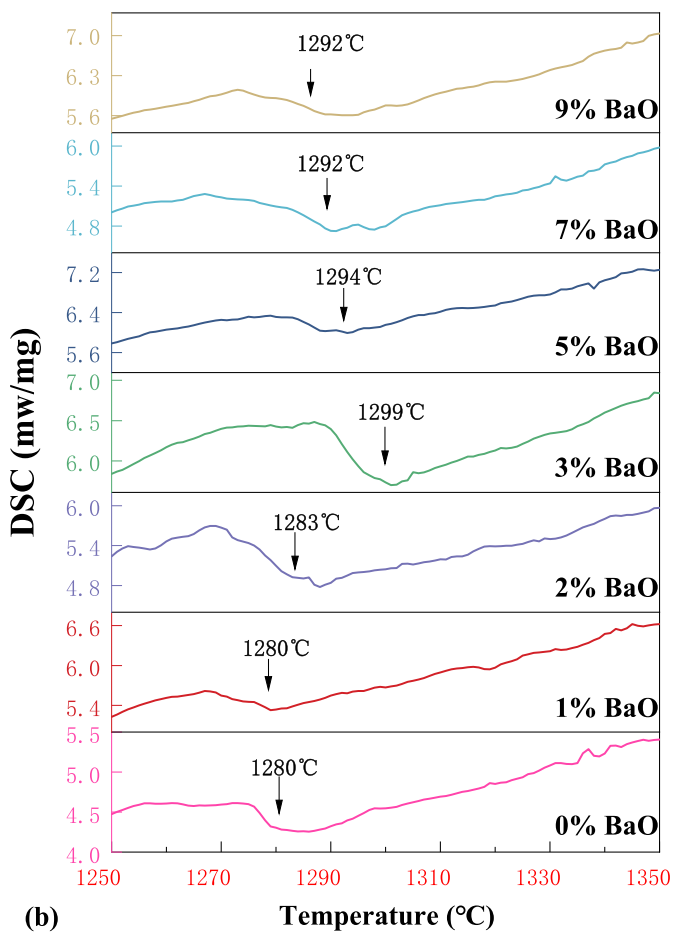

(b)

Fig. 7. (a) The DSC method is used to estimate the eutectic melting temperature of CF by the heat flow in air atmosphere. (b) The DSC method is used to estimate the decomposing temperature of SFCA by the heat flow in air atmosphere. (Online version in color.)
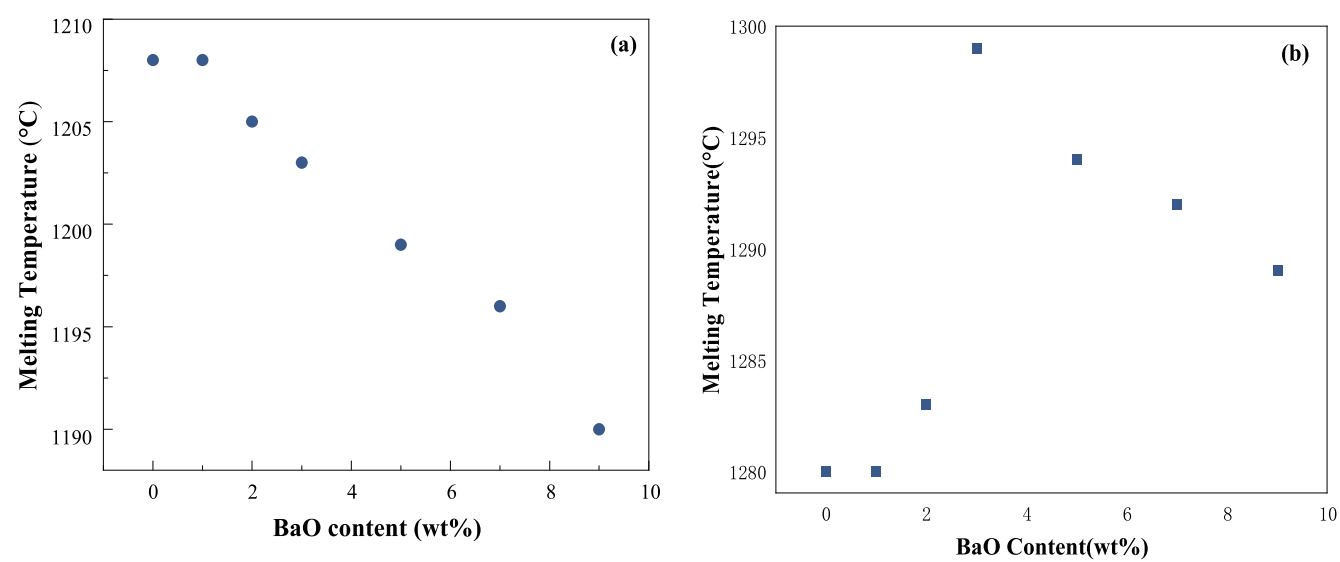

Fig. 8. (a) The eutectic melting temperature curve of $\mathrm{CF}$ with increase in $\mathrm{BaO}$ addition determined by the DSC method in inert atmosphere. (b) The decomposing temperature curve of SFCA with increase in $\mathrm{BaO}$ addition determined by the DSC method in inert atmosphere. (Online version in color.)

$\mathrm{BaO}$ was dissolved in the $\mathrm{CaO}-\mathrm{Fe}_{2} \mathrm{O}_{3}-\mathrm{Al}_{2} \mathrm{O}_{3}-\mathrm{SiO}_{2}$ system to form complex barium-containing SFCA. The eutectic melting temperature of the $\mathrm{CF}$ and $\mathrm{C}_{2} \mathrm{~F}$ declined in the samples as shown in Fig. 8(a). The eutectic melting temperature of the $\mathrm{CF}$ and $\mathrm{C}_{2} \mathrm{~F}$ was showed in Fig. 8(a). It could be observed that the eutectic melting temperature of the $\mathrm{CF}$ and $\mathrm{C}_{2} \mathrm{~F}$ reduced with the addition of $\mathrm{BaO}$. According to the regular pattern of phases transition, it could obtain that the content of $\mathrm{CF}$ reduced in the sintering process. And, the $\mathrm{CF}$ transformed into $\mathrm{C}_{2} \mathrm{~F}$ and $\mathrm{L}$ under high temperature that the reaction was Eq. (6).

$$
\mathrm{CF} \rightarrow \mathrm{C}_{2} \mathrm{~F}+\mathrm{L}
$$

where $\mathrm{L}$ is liquid phase. The ratio of $\mathrm{C}_{2} \mathrm{~F}$ increased in the $\mathrm{CF}$ and $\mathrm{C}_{2} \mathrm{~F}$ system, which would decline the eutectic temperature of $\mathrm{CF}$ and $\mathrm{C}_{2} \mathrm{~F}$. The DSC curves of SFCA was showed in Fig. 7(b), it could be seen that the area of endothermic peak of SFCA decreased with the content of $\mathrm{BaO}$ exceeded 2 mass $\%$, suggesting that the formation of the SFCA liquid phase declined. The temperature trend of SFCA was showed in Fig. 8(b), it could be seen that the decomposing temperature of SFCA went up with the content of $\mathrm{BaO}$ exceeded 2 mass $\%$, which indicated that the stability of SFCA reduced at high temperature. Thus, the content of SFCA decreased with the addition of $\mathrm{BaO}$. The $\mathrm{FB}$ solid solution was precipitated from the $\mathrm{CaO}-\mathrm{Fe}_{2} \mathrm{O}_{3}-\mathrm{Al}_{2} \mathrm{O}_{3}-\mathrm{SiO}_{2}$ system and a small amount of $\mathrm{Al}^{3+}$ migrated from SFCA to $\mathrm{FB}$, which was consistent with the results described in SEM-EDS. The results explained the fact why the SFCA peak area reduced first and decreased then on the DSC curves with increased the content of $\mathrm{BaO}$. SFCA was one of the most maximum produced minerals in iron ore sintering and had been considered as the main bonding phase during the production of industrial iron ore sinters. ${ }^{5,9)}$ Therefore, less liquid phase 


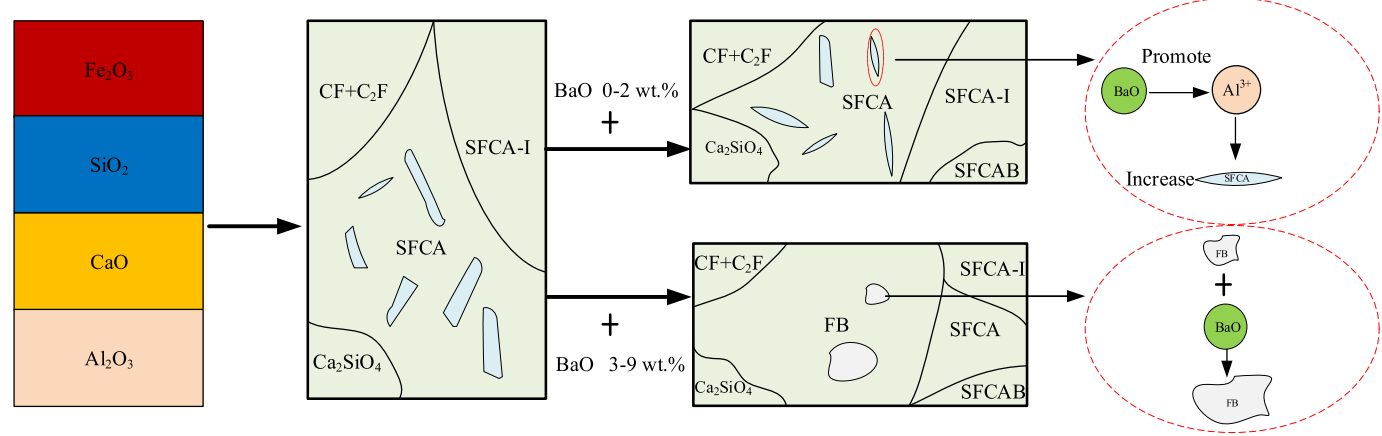

Fig. 9. mechanism of action of $\mathrm{BaO}$ in sinter. (Online version in color.)

reduced the bonding strength of the sinter.

\section{REFERENCES}

\subsection{Mechanism Analysis}

Figure 9 indicated that $\mathrm{BaO}$ plays an important role in microstructures of SFCA. To determine the change mechanism, the morphology of SFCA with different $\mathrm{BaO}$ contents was elucidated. As depicted in Fig. 9, the mechanisms for the formation of by added $\mathrm{BaO}$ were explained. A little of $\mathrm{BaO}$ participated in the solid solution reaction of SFCA with the content of $\mathrm{BaO}$ was 1 mass $\%, 2$ mass $\%$, respectively. The existence of $\mathrm{Ba}^{2+}$ absorbed part of $\mathrm{Al}^{3+}$ into SFCA, which increased the formation of needle-like SFCA. When the $\mathrm{BaO}$ content from 3 mass $\%$ to 9 mass $\%$, the most $\mathrm{BaO}$ reacted directly with $\mathrm{Fe}_{2} \mathrm{O}_{3}$ to form $\mathrm{FB}$. The $\mathrm{Si}^{4+}$-free $\mathrm{FB}$ was precipitated from the SFCA phase and a larger amount of silica was present in the SFCA bonding phase, which indicated that the barium prevented the solid solution behavior of $\mathrm{Si}^{4+}$.

\section{Conclusions}

To investigate the effect of $\mathrm{BaO}$ on formation mechanisms of silico-ferrite of calcium and aluminum, the phase composition of the samples was determined by XRD, SEM-EDS, and TG-DSC. The results were summarized as follows:

(1) $\mathrm{BaO}$ promoted the formation of needle-like SFCA and increased the decomposing temperature of SFCA with the amount of $\mathrm{BaO}$ increased to 2 mass $\%$.

(2) New bonding phase FB was generated with the amount of $\mathrm{BaO}$ exceeded 2 mass $\%$. The decomposing temperature of SFCA significantly decreased, but still higher than the original temperature. However, $\mathrm{BaO}$ pushed the formation of $\mathrm{C}_{2} \mathrm{~F}$ in the $\mathrm{CF}$ and $\mathrm{C}_{2} \mathrm{~F}$ system, which decreased the eutectic melting temperature of $\mathrm{CF}$ and $\mathrm{C}_{2} \mathrm{~F}$.

(3) The quality of sinter ore was improved when $\mathrm{BaO}$ content less than 2 mass $\%$. With the further increase of $\mathrm{BaO}$ content, which could decrease the strength of sinter and was harmful for the quality of sinter.

\section{Acknowledgments}

The present work was financially supported by National Nature Science Foundation of China (Grant No. 2019M663932XB) and Natural Science Basic Research Program of Shaanxi (Program No. 2019JLP-05).
1) N. A. S. Webster, M. I. Pownceby, I. C. Madsen and J. A. Kimpton: ISIJ Int., 53 (2013), 774. http://doi.org/10.2355/isijinternational.53.774

2) T. R. C. Patrick and R. R. Lovel: ISIJ Int., 41 (2001), 128. http://doi. org/10.2355/isijinternational.41.128

3) L. X. Yang and C. E. Loo: ISIJ Int., 37 (1997), 449. https://doi. org/10.2355/isijinternational.37.449

4) H. S. Kim, J. H. Park and Y. C. Cho: Ironmaking Steelmaking, 29 (2002), 266. https://doi.org/10.1179/030192302225004511

5) T. R. C. Patrick and M. I. Pownceby: Metall. Mater. Trans. B, 33 (2002), 79. https://doi.org/10.1007/s11663-002-0088-0

6) K. Sugiyama, A. Monkawa and T. Sugiyama: ISIJ Int., 45 (2005), 560. https://doi.org/10.2355/isijinternational.45.560

7) X. D. Xing, Y. L. Du, J. L. Zheng, S. Wang, S. Ren and J. T. Ju: JOM, 73 (2021), 1328. https://doi.org/10.1007/s11837-021-04628-8

8) R. Mežibrický and M. Fröhlichová: ISIJ Int., 56 (2016), 1111. https:// doi.org/10.2355/isijinternational.ISIJINT-2016-044

9) I. Tonžetić and A Dippenaar: Miner. Eng., 24 (2011), 1258. https:// doi.org/10.1016/j.mineng.2011.04.012

10) W. G. Mumme, J. M. F. Clout and R. W. Gable: Neues Jahrb. für Mineral. Abhandlungen, 173 (1998), 93. https://doi.org/10.1127/ njma/173/1998/93

11) K. Yajima and S. M. Jung: ISIJ Int., 52 (2012), 535. https://doi. org/10.2355/isijinternational. 52.535

12) K. Zöll, T. Manninger, V. Kahlenberg, H. Krüger and P. Tropper: Metall. Mater. Trans. B, 48 (2017), 2207. https://doi.org/10.1007/ s11663-017-0988-7

13) M. I. Pownceby, N. A. S. Webster and J. R. Manuel: Miner. Process. Extr. Metall., 125 (2016), 140. https://doi.org/10.1080/03719553.201 6.1153276

14) N. A. S. Webster, M. I. Pownceby, R. Pattel, J. R. Manuel and J. A. Kimpton: ISIJ Int., 59 (2019), 263. https://doi.org/10.2355/ isijinternational.ISIJINT-2018-573

15) X.-y. Li, B.-X. Su, L.-g. Xia, J.-1. Zhang and H.-w. Guo: J. Iron Steel Res. Int., 22 (2015), 478. https://doi.org/10.1016/S1006706X(15)30030-3

16) N. A. S. Webster, J. G. Churchill, F. Tufaile, M. I. Pownceby, J. R. Manuel and J. A. Kimpton: ISIJ Int., 56 (2016), 1715. https://doi. org/10.2355/isijinternational.ISIJINT-2016-162

17) L. X. Yang and E. Matthews: ISIJ Int., 37 (1997), 854. https://doi. org/10.2355/isijinternational.37.854

18) T. Maeda, K. Nishioka, K. Nakashima and M. Shimizu: ISIJ Int., 44 (2004), 2046. https://doi.org/10.2355/isijinternational.44.2046

19) Y. F. Chai, W. T. Yu, J. L. Zhang, S. L. An, J. Peng and Y. Z. Wang: Ironmaking Steelmaking, 46 (2019), 424. https://doi.org/10.1080/030 19233.2018.1503629

20) E. A. Mousa, A. Babich and D. Senk: Iron Steel Res. Int., 86 (2015), 1350. https://doi.org/10.1002/srin.201400368

21) N. A. S. Webster, M. I. Pownceby, I. C. Madsen and J. A. Kimpton: Metall. Mater. Trans. B, 43 (2012), 1344. https://doi.org/10.1007/ s11663-012-9740-5

22) N. Yang, X. M. Guo, N. Saito, K. Nakashima and J. T. Zhao: ISIJ Int., 58 (2018), 1406. https://doi.org/10.2355/isijinternational. ISIJINT-2018-028

23) N. V. Y. Scarlett, M. I. Pownceby, I. C. Madsen and A. N. Christensen: Metall. Mater. Trans. B, 35 (2004), 929. https://doi. org/10.1007/s11663-004-0087-4

24) C. Ding, X. Lv, Y. Chen, G. Li, W. He and X. Lv: J. Alloys Compd., 789 (2019), 537. https://doi.org/10.1016/j.jallcom.2019.02.325

$25)$ Z. Wang, D. Pinson, S. Chew, B. J. Monaghan, M. I. Pownceby, N. A. S. Webster, H. Rogers and G. Q. Zhang: ISIJ Int., 56 (2016), 1138. https://doi.org/10.2355/isijinternational.ISIJINT-2015-598

26) Z. G. Pang, X. D. Xing, J. L. Zheng, Y. L. Du, S. Ren and M. Lv: J. Non-Cryst. Solids, 571 (2021), 121071. https://doi.org/10.1016/j. jnoncrysol.2021.121071 